UCRL-JC-123283

PREPRINT
CONF $-960543 \% \%$

\title{
X-Ray Diagnostics of Hohlraum Plasma Flow
}

C. A. Back, S. H. Glenzer, O. L. Landen,

B. J. MacGowan, and T. D. Shepard

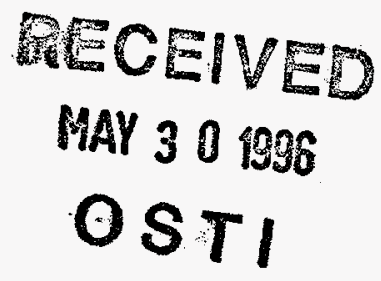

This paper was prepared for submittal to the

11th Topical Conference on High Temperature Plasma Diagnostics

Monterey, California

May 12-16, 1996

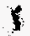

May 13, 1996

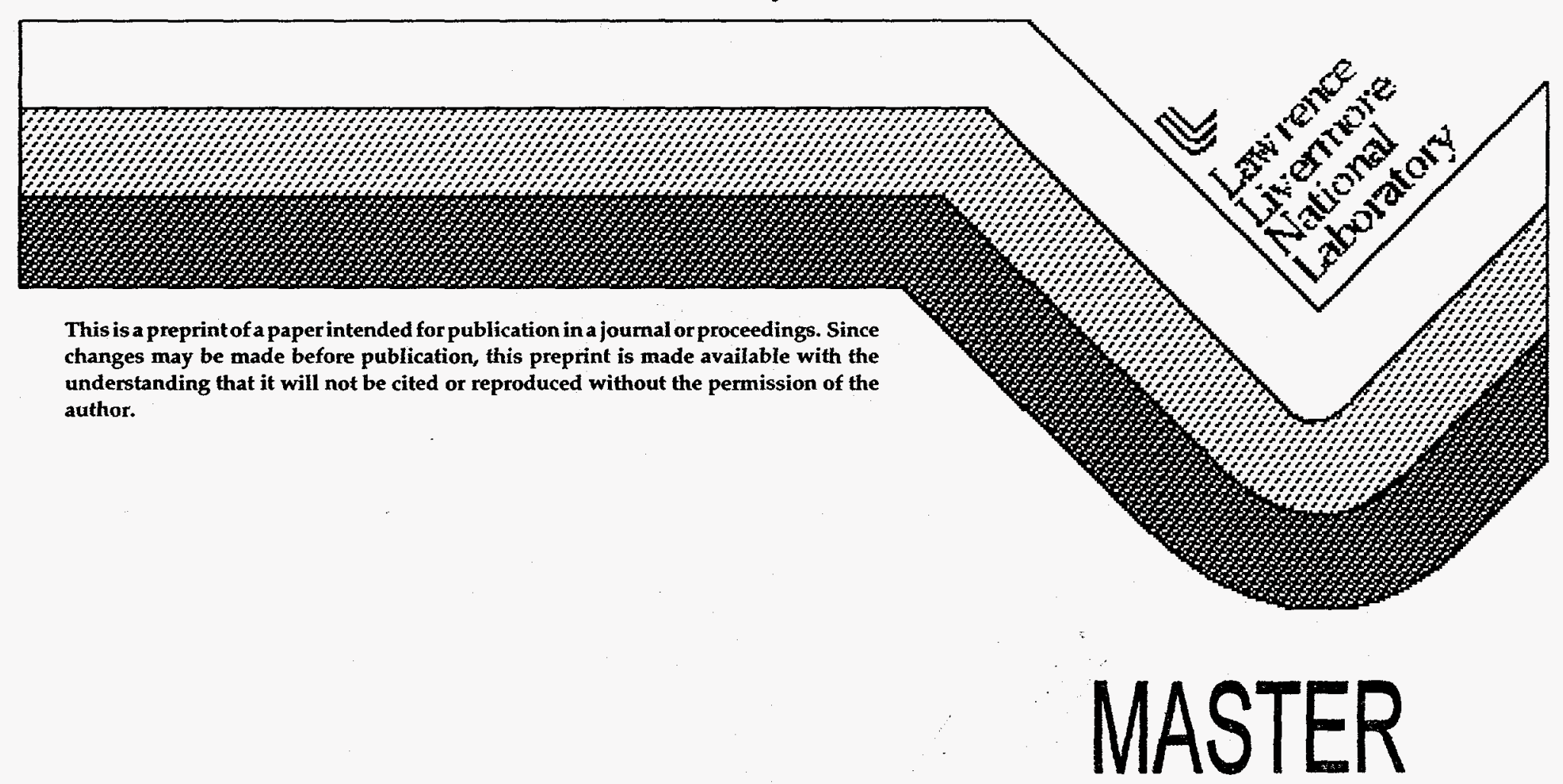




\section{DISCLAIMER}

This document was prepared as an account of work sponsored by an agency of the United States Government. Neither the United States Government nor the University of California nor any of their employees, makes any warranty, express or implied, or assumes any legal liability or responsibility for the accuracy, completeness, or usefulness of any information, apparatus, product, or process disclosed, or represents that its use would not infringe privately owned rights. Reference herein to any specific commercial product, process, or service by trade name, trademark, manufacturer, or otherwise, does not necessarily constitute or imply its endorsement, recommendation, or favoring by the United States Government or the University of California. The views and opinions of authors expressed herein do not necessarily state or reflect those of the United States Government or the University of California, and shall not be used for advertising or product endorsement purposes.

$\boldsymbol{l}$ 


\title{
X-ray Diagnostics of Hohlraum Plasma Flow
}

\author{
C. A. Back, S. H. Glenzer, O. L. Landen, \\ B. J. MacGowan, and T. D. Shepard \\ Lawrence Livermore National Laboratory, P.O. Box 808, Livermore, CA 94551
}

In this study we use spectroscopy and $\mathrm{x}$-ray imaging to investigate the macroscopic plasma flow in mm-sized laser-produced hohlraum plasmas. - By using multiple diagnostics to triangulate the emission on a single experiment, we can pinpoint the position of dopants placed inside the hohlraum. X-ray emission from the foil has been used in the past to measure electron temperature. Here we analyze the spatial movement of dopant plasmas for comparison to hydrodynamic calculations.

Modeling of hohlraums is essential to the design of targets for inertial confinement fusion research. The non-planar, convergent geometry of the targets has led to the use of "integrated" modeling which is necessary to correctly determine the radiation fields that drive the fusion process. Recent measurements have found discrepancies in radiation drive as measured by the radiation temperature, $T_{r}$. During the beginning of a shaped $2.2 \mathrm{~ns}$ pulse, the measured $\mathrm{T}_{\mathrm{r}}$ is found to be higher than calculated by hydrodynamic calculations, while at the end the $T_{r}$ is lower. 1 
Recently, electron temperatures of the confined laser-produced plasmas have been measured. ${ }^{2}$ These targets typically achieve electron temperatures that temporally evolve from 2 to $4 \mathrm{keV}$ and electron densities $\sim 10^{21} \mathrm{~cm}^{-3}$. We have found that the laser heating of these small targets produces significant time-dependent effects. Also recent measurements have found some inconsistencies between the experimental temperature and the modeling.

The study of the plasma flow aids in the interpretation of the hohlraum environment because the confined geometry and the shaped laser pulse affect the macroscopic motion of the plasma. Measurements of these targets are difficult due to obstructed lines-ofsight and rapidly changing conditions. Nevertheless, knowledge of the spatial position is important for proper comparisons with simulations.

In these experiments, $\mathrm{X}$-ray emission of a dopant plasma are tracked by $x$-ray spectrometers and $x$-ray imagers. Dopants are good "markers" for tracking because they provide local information of the plasma without causing large perturbations. The dopants are $2000 \AA$ deposits of $\mathrm{TiCr}$ which produce emission in the 2.8 to $1.8 \AA$ regime. For our plasma conditions, they are quickly ablated and entirely vaporized in $<300$ ps. Since the emission comes from the K-shell of $\mathrm{Ti}$ and $\mathrm{Cr}$, the emission volume is not extremely sensitive to expected changes in the plasma conditions. Therefore, it is useful to track local movement from a known initial position.

The targets were scale- 1 hohlraums that were $2.75 \mu \mathrm{m}$ long and 1.6 $\mathrm{mm}$ in diameter. Laser beams enter into the ends of the cylindrical 
target and deliver $20-25 \mathrm{~kJ}$ of energy in a $2.2 \mathrm{~ns}$ long pulse. The design of these types of targets are described in other papers 3 , but the important aspect of modeling to this study is the movement of the $\mathrm{Au} /$ gas interface and the dopant foil in the region dominated by laser ablation.

Figure 1 shows a schematic of the hohlraum. The inside wall of the hohlraum is ablated by the laser and by $x$-rays. The lasers irradiate $<20 \%$ of the hohlraum wall. To track the dopant, diagnostic holes are cut into the hohlraum for the spectrometers. In addition, the plasma is viewed through the laser entrance holes of the target. The position of the dopant foil is also shown in the figure.

By using multiple diagnostics to triangulate the x-ray emission, we can determine the position of the dopants placed inside the hohlraum with an accuracy of $75 \mu \mathrm{m}$. The diagnostics are a combination of streaked and gated $x$-ray pinhole cameras ${ }^{4}$ and gated $x$-ray spectrometers. 5 The pinhole cameras provide $x$-ray images of the dopant foil and the expanding plasma, while spectrometers provide spatial information in one-dimension and spectral information in the perpendicular dimension.

The advantage of using spectrometers is that it allows us to distinguish between background $\mathrm{x}$-rays from the $\mathrm{Au}$ wall and the dopant $\mathrm{x}$-rays. In the demonstration of this technique, we will take a target in which the foil is placed in the beam path on one side of the hohlraum. A single line-of-sight is not sufficient to determine the plasma motion because the plasma may be moving axially as well as 
radially. To triangulate the motion, three spectrometers are positioned to have resolution in orthogonal directions. These will be specified as view $A, B$, and $C$.

Figure 2 shows the images from a spectrometer (View A) at two different times. The spatial resolution of this spectrometer is in the vertical direction. Here we see that the emission of the He-like $n=2-1$ resonance line is emitted from the two spots where the beas intersect the foils at time $\mathrm{t}=\mathrm{t} \varnothing+0.8 \mathrm{~ns}$. However, $1 \mathrm{~ns}$ later, the two emission regions migrate towards the center where they merge into one emission region. The peak temperature at this time is $4.5 \mathrm{keV} .6$

The second line-of-sight (View B) down the laser axis clearly shows motion towards the center of the hohlraum. From this line-of-sight the spatial resolution was in the horizontal plane and the diagnostic records emission from two different foils, labelled 1 and 2 in figure 1. An example of the data is shown in figure 3. The emission from the two foils move symmetrically towards the center of the hohlraum. By the end of the laser pulse, at $2 \mathrm{~ns}$, the two plasmas merge into one at the hohlraum axis.

The third line-of-sight (View C) was perpendicular to the hohlraum axis. In this dimension, an x-ray streak camera was used to record the emission above $2.5 \mathrm{keV}$ through a diagnostic hole in the hohlraums. The edge-on view of the dopant allows a measurement of the $\mathrm{x}$-ray emission along the hohlraum axis. In this direction, the spatial motion is not expected to be large. Therefore used a x-ray pinhole streak camera for high spatial resolution. This detector used 
one dimension for temporal resolution and the other for $10 \mathrm{X}$ spatial magnification. The pinhole was filtered for $x$-rays $>2.5 \mathrm{keV}$. The data are shown in figure 4 where the edge of the foil is clearly visible at $x=0.9 \mathrm{~mm}$. The edge of the foil remains stationary throughout the laser pulse. Background emission does start to become a problem late in time because it is not spectrally resolved from the foil emission. Based on this data, we find there is no large shift in the center-of-mass of the target along the hohlraum axis.

The three views, A, B, and C, of the dopant plasma show that the plasma dopant moves radially towards the center of the hohlraum. View A and B distinctly show the movement of the dopant towards the center, while view $C$ eliminates motion out of the laser entrance hole. The radial motion is shown in Figure 5 as a function of time for two different gas filled targets. The initial position of the dopant edge is at $600 \mu \mathrm{m}$ because this is the radius of the hohlraum laser entrance hole. The dopant in the higher density gas, propane, mores more slowly towards the center than the dopant in the methane gas. At 1.5 ns which corresponds to the peak of the pulse, we find the that the methane allows the $\mathrm{Au}$ to expand at a rate 1.4 times as fast as the propane. These results are consistent with the higher density gas holding back Au plasma which pushes in from the wall of the hohlraum.

In conclusion, this technique of triangulation can be used to quantify the plasma flow. In this case, measuring the movement of bulk plasmas is important for understanding related measurements of 
electron temperature in these scale-1 hohlraums. Calculations do show movement of the dopant towards the center of the hohlraum and comparisons are in progress. Understanding the plasma flow will help in the study of the $\mathrm{Au} / \mathrm{gas}$ interface motion as well as in the electron temperature measurements. We are continuing to develop these techniques to enable better comparisons of simulations to measurements.

\section{Acknowledgements}

We thank the Nova target fabrication and laser operations crew for tirelessly working to make these experiments possible. This work was performed under the auspices of the U.S. Department of Energy by the Lawrence Livermore National Laboratory under Contract No. W-7405ENG-48. 


\section{Figure Captions}

Figure 1. Schematic of the hohlraum. The three lines-of-sight for the triangulation of the plasma motion are identified as View A, View $B$, and View C.

Figure 2. Data from view A showing $x$-ray emission of the He-like $\mathrm{n}=2-1$ resonance transition of $\mathrm{Cr}$ on a dopant strip. The data on the bottom at $t=0.8$ ns shows two distinct spots while the data on the top at $t=1.5$ ns show the two spots merged.

Figure 3. X-ray emission from two foils shown taken from View B. At the end of the pulse, the intensity two foils have merged into one indicating radial motion of the foil.

Figure 4. X-ray emission $>2.5 \mathrm{keV}$ from View C. The $\mathrm{x}$-ray streak camera shows the foil emission is stationary along the $\mathrm{E} / \mathrm{W}$ axis.

Figure 5. The emission of the outside edge of the dopant emission as a function of time. The laser pulse is $2.2 \mathrm{~ns}$ long and the maximum discrepancy at $1.5 \mathrm{~ns}$ occurs at the peak of the pulse. The data is taken from View A.

\section{References}


${ }^{1}$ L. J. Suter, et al. accepted for publication in Physics of Plasmas.

${ }^{2}$ C. A. Back et al., submitted for pulication in Phys. Rev. Lett.

${ }^{3}$ L . V. Powers, et al. Phys. of Plas. 2, 2473 (1995)

4J. D. Kilkenny, Laser and Part. Beams 9, 49 (1991); D. K. Bradley, et al.

Rev. Sci. Instrum. 63, 4813 (1992); O. L. Landen, et al. "Gain uniformity, linearity, saturation and depletion in gated microchannel-plate $x$-ray framing cameras: in Ultrahigh- and High-Speed Phyotography, Videography, and Photonics '93, SPIE vol 2002, p. 2 (SPIE, Bellingham WA, 1993).

${ }^{5}$ C. A. Back, et al., Rev. Sci. Instrum. 66, 764 (1995).

${ }^{6} \mathrm{C}$. A. Back, et al., to be published in the proceedings of the Atomic Processes in Dense Plasmas 1996. 

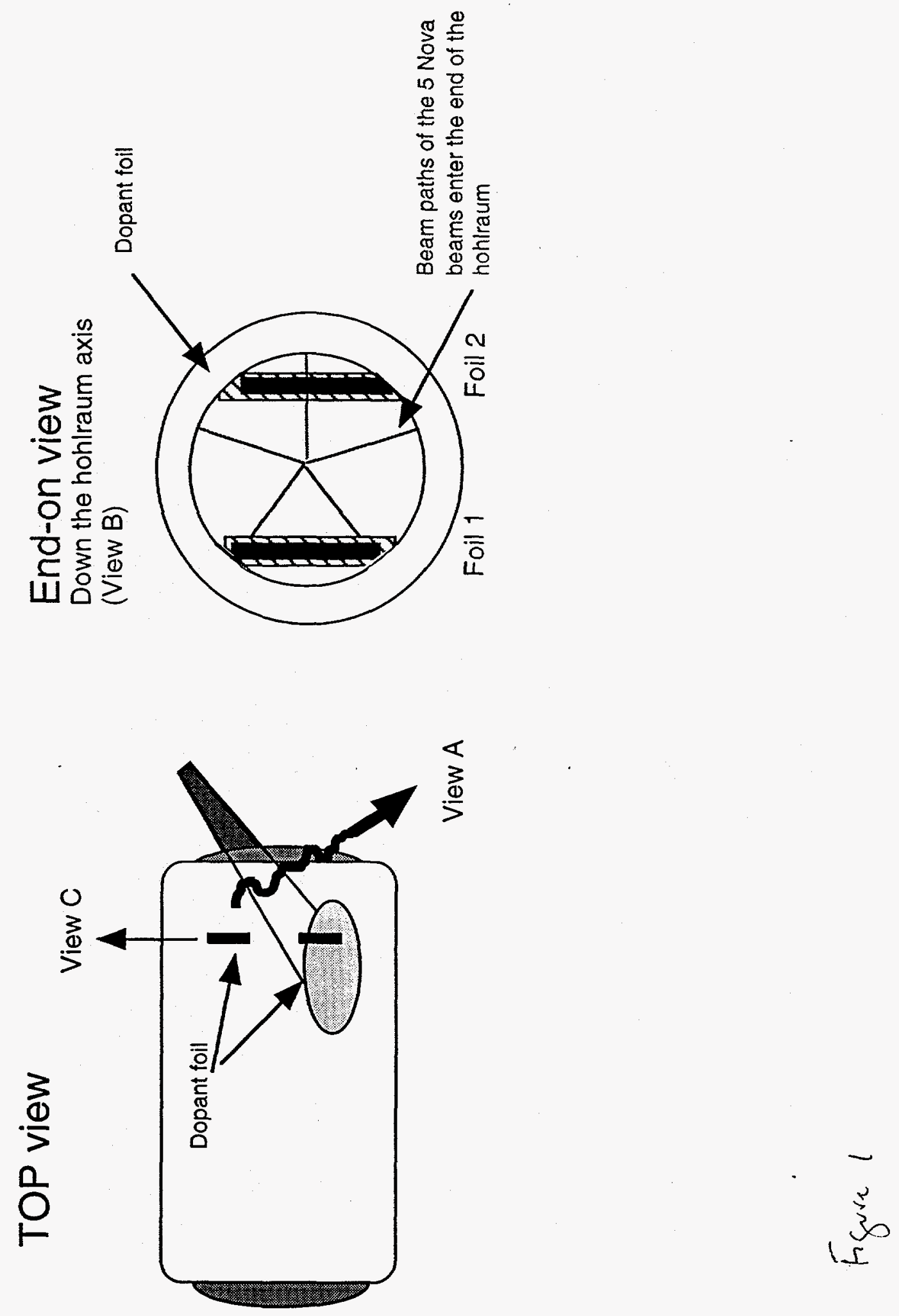


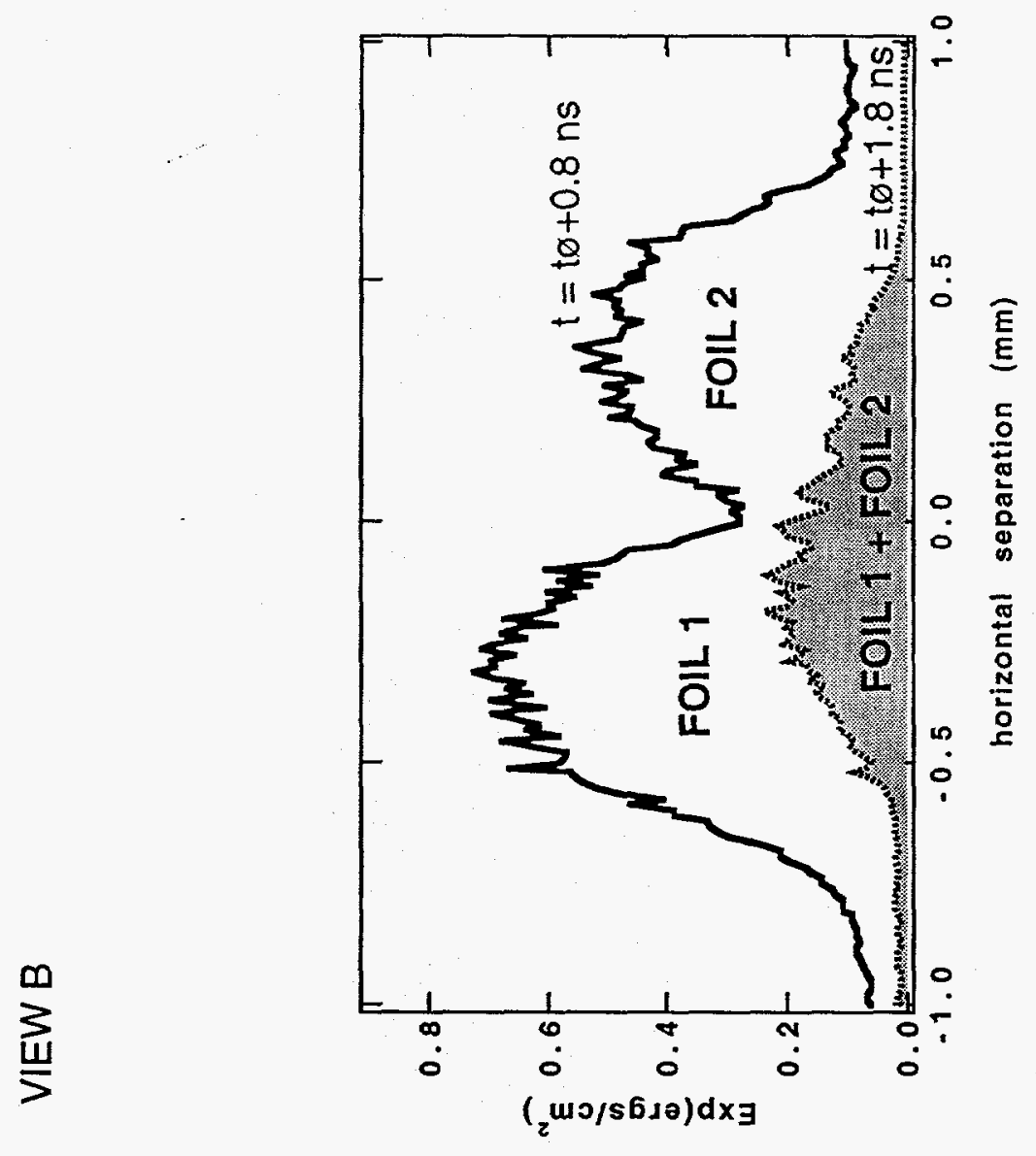

0
0
$\frac{0}{3}$
$i \frac{0}{4}$ 


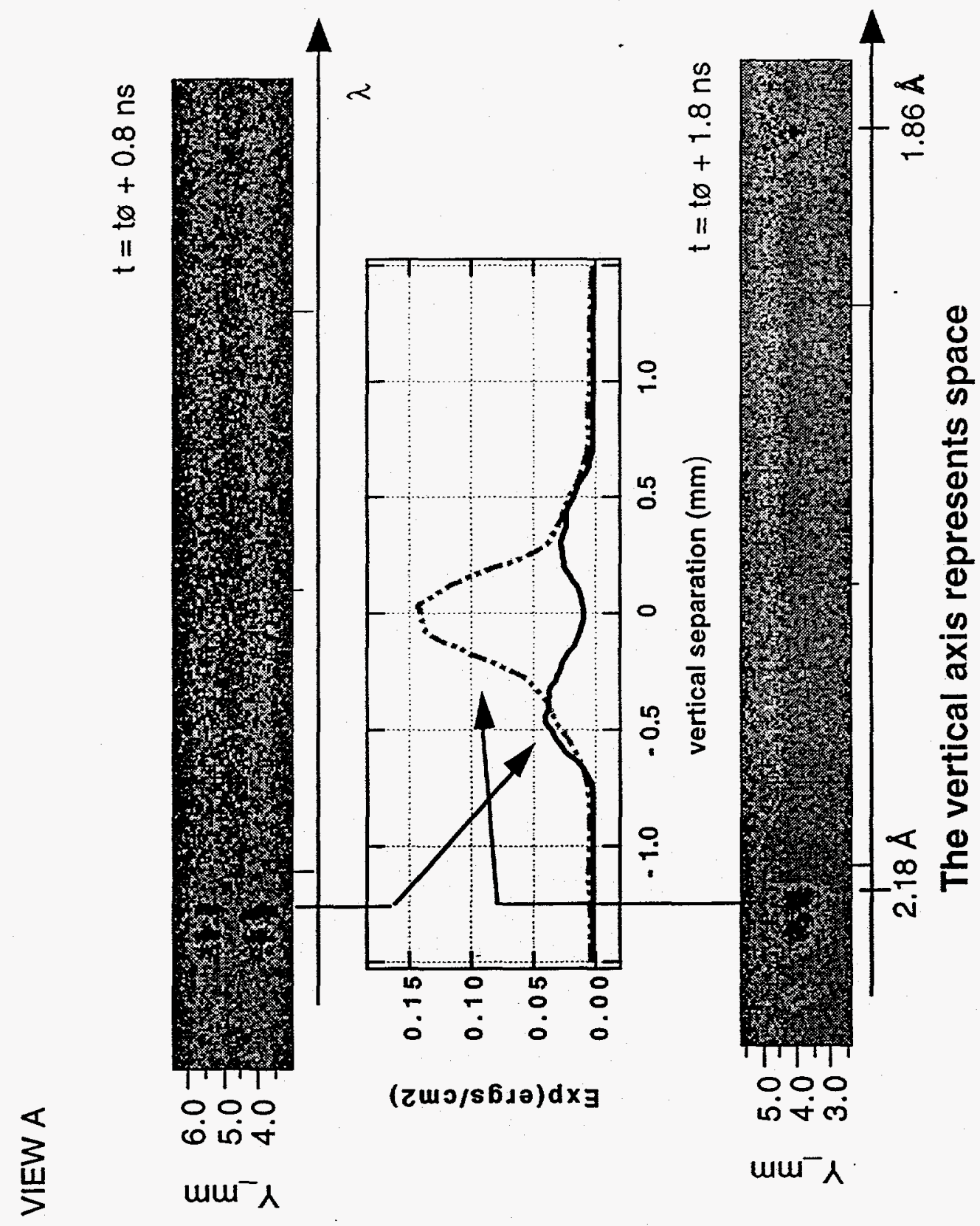

일 


\section{View C}

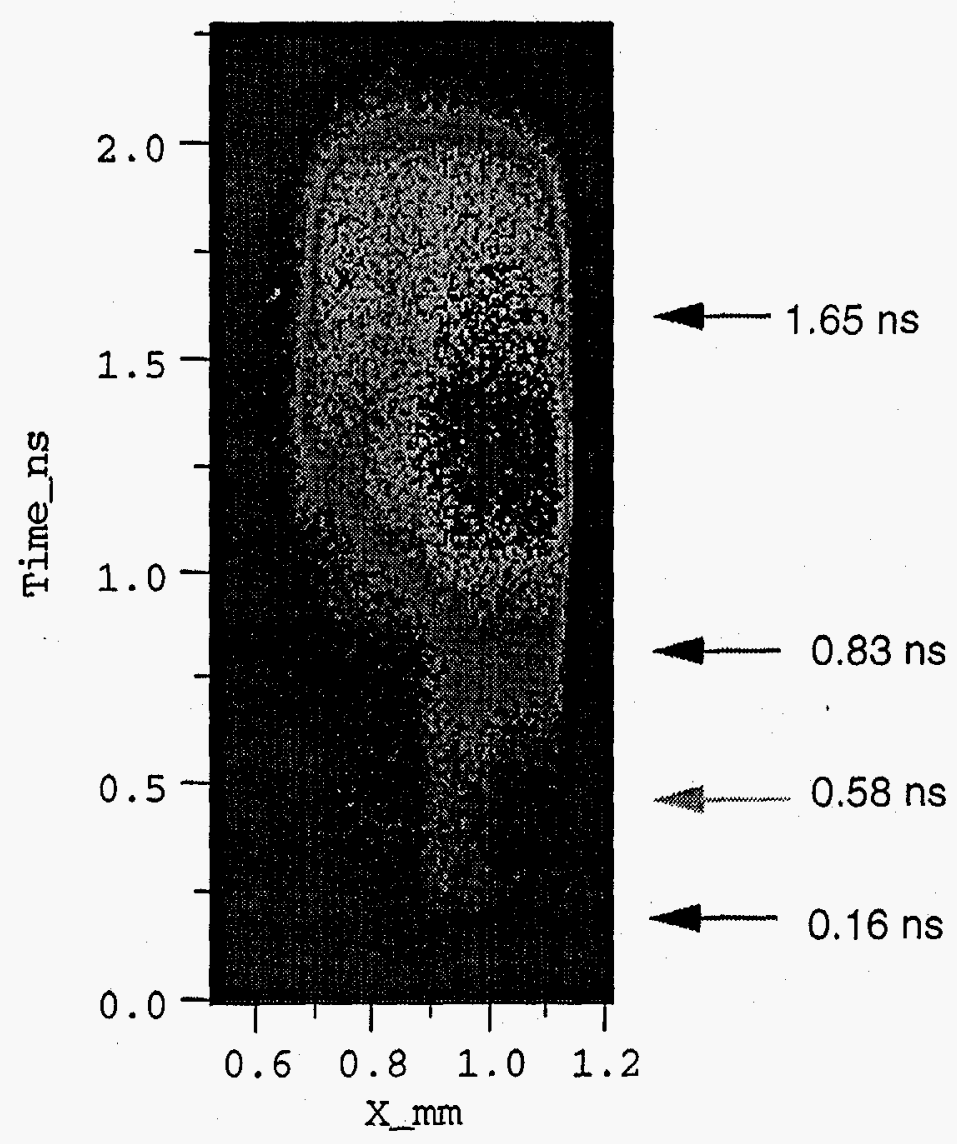

Foil edge is stationary along the EN axis
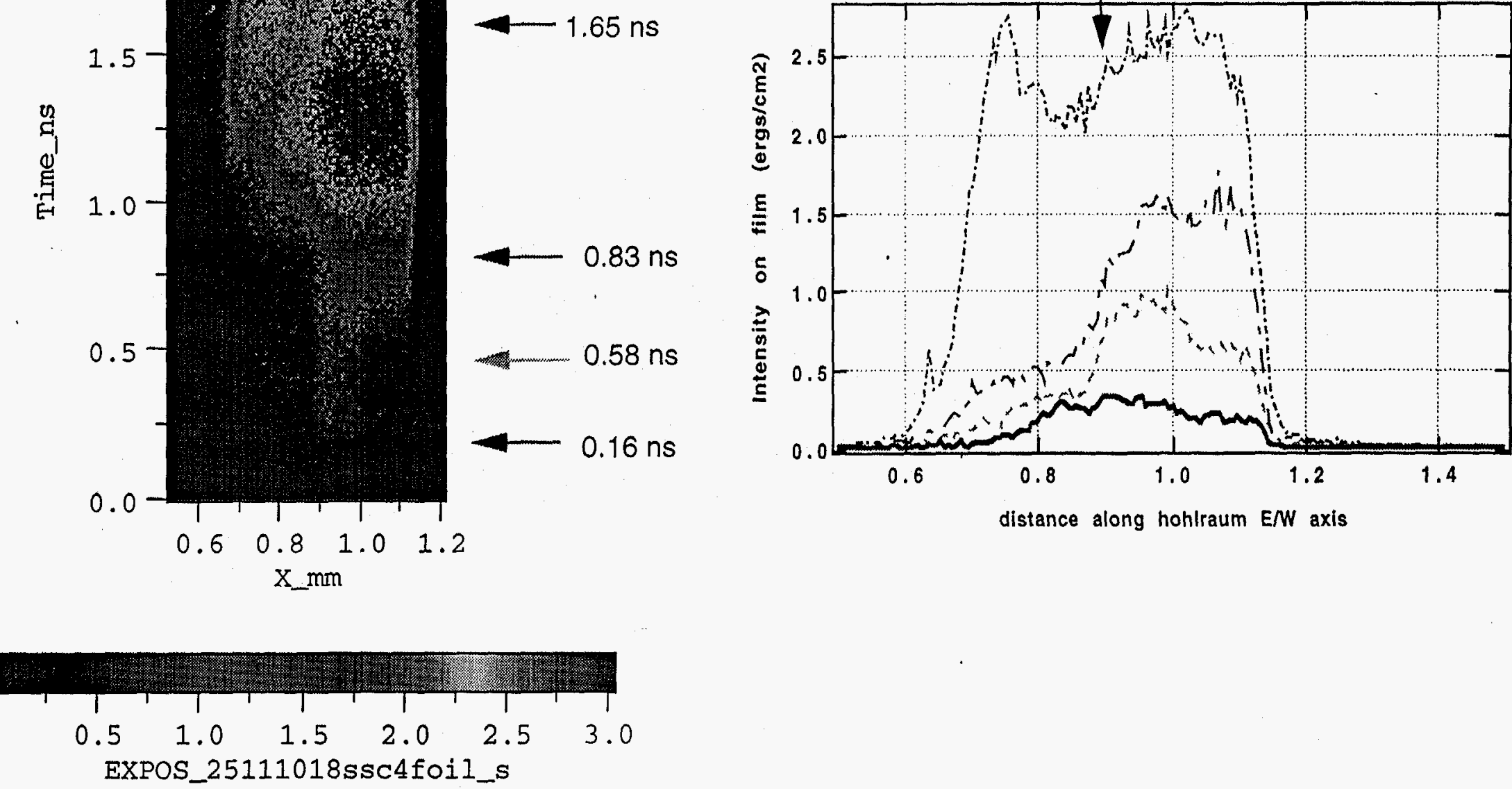

Figure 4 


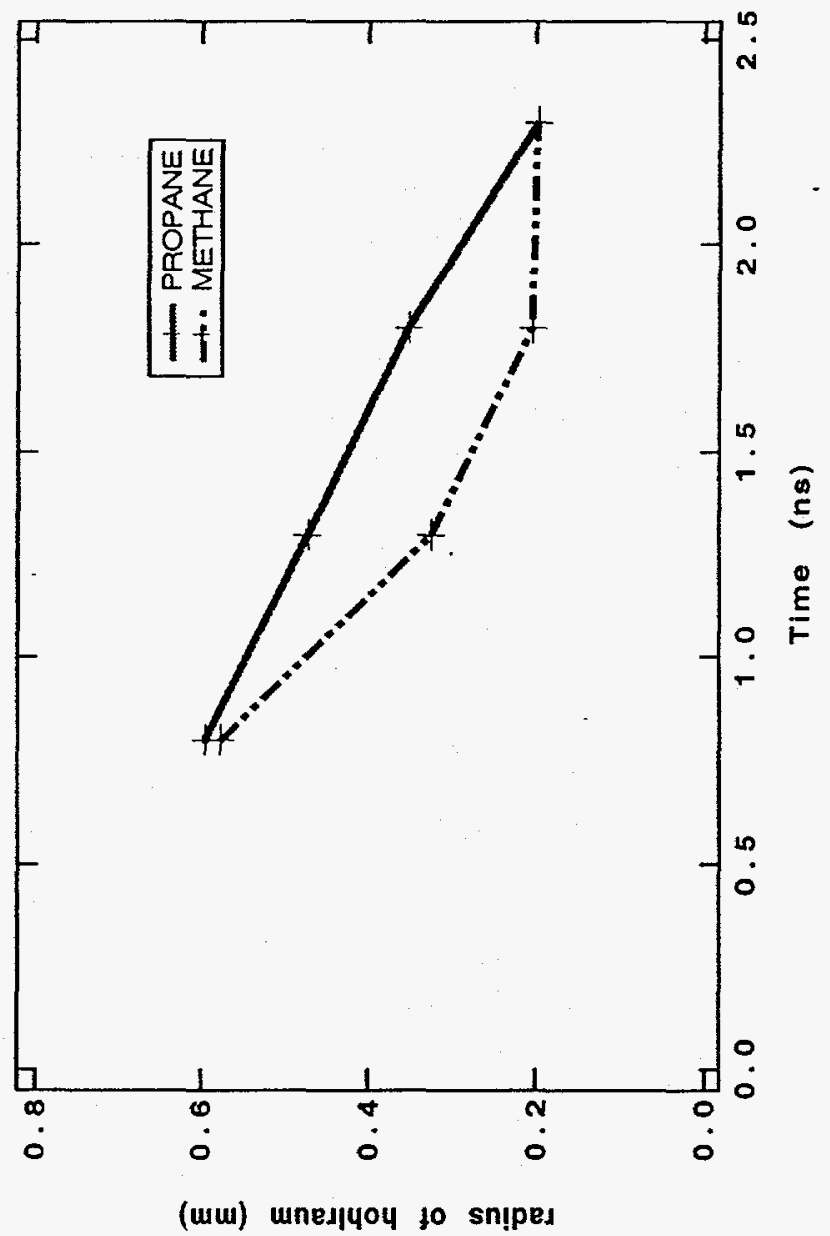




